Revista Tecné, Episteme y Didaxis: TED. Año 2014, Número Extraordinario. ISSN Impreso: 0121-3814, ISSN web: 2323-0126

Memorias, Sexto Congreso Internacional sobre Formación de Profesores de Ciencias. 08 al 10 de octubre de 2014, Bogotá

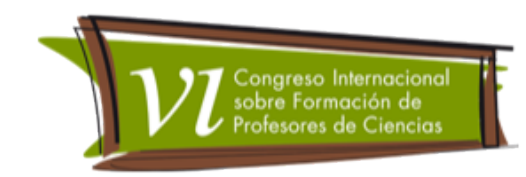

\title{
Un acercamiento a la naturaleza de los conocimientos prácticos en la formación inicial de profesores de ciencias. Reflexión teórica. ${ }^{1}$
}

Sánchez Hernández María Elvira²

Categoría 1. Reflexiones y experiencias desde la innovación en el aula.

\section{Resumen}

En esta comunicación se presentan algunas reflexiones elaboradas a partir de los fundamentos teóricos relacionados con el conocimiento práctico de los docentes, al interior de las dinámicas que se generar en los procesos de formación inicial de los profesores de ciencias. Se hace un breve recorrido por la importancia y el desarrollo que han tenido los programas de formación de profesores en etapa inicial, desde la perspectiva de los conocimientos profesionales de los docentes, y en particular de los conocimientos prácticos que de ellos devienen, particularmente, teniendo en consideración las corrientes propuestas por Donald Schön y Jean Clandinin. Finalizamos con algunas consideraciones importantes para el campo de estudio en cuestión.

\section{Palabras Clave}

Conocimientos prácticos, formación inicial de profesores, práctica profesional docente.

\section{Introducción: La formación de profesores.}

Los espacios académicos de práctica docente, propios de los programas de formación de profesores, se han visto desvirtuados y convertidos en escenarios donde la interacción y la puesta en escena de los resultados en la investigación

\footnotetext{
1 Este artículo es resultado del Proyecto de Investigación titulado "La naturaleza del conocimiento práctico de los profesores de química: aportes a la formación inicial", financiado por la Vicerrectoría de Investigación, Innovación, Creación, Extensión y Proyección Social de la Universidad Distrital Francisco José de Caldas, mediante el Acta Compromisoria No. 76 de 2013. Código 4-284-419-13, bajo la Modalidad de Apoyo a los Trabajos de Maestría (Convocatoria No. 07 de 2013).

2 Universidad Distrital Francisco José de Caldas. mariaesh@gmail.com.
} 
Revista Tecné, Episteme y Didaxis: TED. Año 2014, Número Extraordinario. ISSN Impreso: 0121-3814, ISSN web: 2323-0126

Memorias, Sexto Congreso Internacional sobre Formación de Profesores de Ciencias. 08 al 10 de octubre de 2014, Bogotá

educativa se aíslan de las realidades educativas. Estos programas de formación inicial tienen poca incidencia en la transformación de los procesos educativos, ya que por lo general solo se enfatiza en la transmisión de contenidos y metodologías, dejando de lado otros aspectos que influyen en las realidades docentes (Gimeno-Sacristán, 1997a). Al respecto se considera

\begin{abstract}
"Los profesores noveles conocen muchos principios generales teóricos, pero no saben cómo ponerlos en práctica cuando han de responder a las necesidades de unos alumnos concretos en situaciones únicas de modo que éstos, cuando agotan sus escasos recursos, adoptan los modelos de enseñanza tradicionales conocidos porque les ofrecen la seguridad necesaria para sobrevivir" (Benejeman, 1993: 345)
\end{abstract}

Mosquera y Furió-Mas (2008) proponen que la investigación desde la Didáctica de las Ciencias sobre Formación de profesores, no basta con limitarla a que se conozcan nuevos modelos metodológicos. Se requiere que el propio profesorado es quien debe identificar y cuestionar de forma argumentada su actividad docente habitual para dar cuenta de las necesidades de cambios.

Se puede asumir entonces, que los problemas de la acción docente, pueden ser resueltos a partir de la reflexión crítica que realizan los y las profesoras sobre su propia práctica.

Schön (1983), propone que el proceso de reflexión sobre esa acción cotidiana es el que genera permanentemente nuevos conocimientos, que luego serán usados en nuevas prácticas. En otras palabras, el profesor debe hacerse consciente de los conocimientos prácticos que ponen en evidencia durante el acto escolar.

El conocimiento práctico y en particular el de los maestros

"combinan, en diferente proporción, aspectos tácitos y explícitos, en uso y proposicionales. En él se conjugan desde esquemas prácticos de acción, hasta principios sostenidos proposicionalmente, que no solo se han visto conformados a través de la experiencia personal como alumno, sino también con el aporte de la formación académica y la 
Revista Tecné, Episteme y Didaxis: TED. Año 2014, Número Extraordinario. ISSN Impreso: 0121-3814, ISSN web: 2323-0126

Memorias, Sexto Congreso Internacional sobre Formación de Profesores de Ciencias. 08 al 10 de octubre de 2014, Bogotá

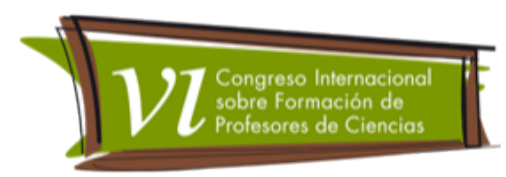

Estas construcciones, aunque con diferente nivel de elaboración consciente, generalidad y organización, son las que permiten dar sentido, significar y orientar la acción del profesor en la práctica (Porlán, 1995).

\section{Desarrollo teórico: ¿Qué son los conocimientos prácticos?}

Cuando los docentes enfrentan las diferentes realidades educativas, no lo hacen solo haciendo uso de los contenidos y de las técnicas aprendidas en los procesos de formación formal. La forma de enseñar depende, como lo afirma Perrenoud (1995) citado por Alliaud (1998), de los pensamientos racionales producto de sus saberes específicos, y de esquemas de reacción menos conscientes, producto de la historia de vida y de la experiencia profesional del profesor. Ambas situaciones se ponen en juego en momentos específicos, y coexisten en el docente.

El maestro necesita saber lo que va a enseñar, necesita saber cómo enseñarlo pero con eso no es suficiente: "los docentes actúan de acuerdo a sus creencias y mecanismos adquiridos culturalmente por vía de la socialización" (GimenoSacristán, 1997b: 107).

Terhart (1987) afirma que en la docencia las influencias informales en la socialización profesional han sido más decisivas que las formales.

En este sentido, una de las líneas de investigación en la Didáctica de las Ciencias se ha orientado hacia la formación de docentes, y particularmente, hacia el interés por la configuración del conocimiento práctico del profesor, que se expresa en situaciones de enseñanza. Pérez Gómez (1988), citado por Rodríguez Marcos (1995:37) lo define como "conjunto idiosincrático y, por tanto, en si mismo coherente, de carácter cognitivo y afectivo, explicativo y normativo, de conocimientos, capacidades, teorías, creencias y actitudes".

El conocimiento práctico es un conocimiento personal que surge de circunstancias, acciones y experiencias que tienen contenido afectivo o relevancia emocional para el individuo así como sentido "experiencial", pues está sujeto al cambio. Tales saberes, ligados a la experiencia personal y al desarrollo profesional de cada sujeto, tienen sin embargo elementos comunes cuando integran los orígenes culturales de los profesores, particularmente, algunos 
Revista Tecné, Episteme y Didaxis: TED. Año 2014, Número Extraordinario. ISSN Impreso: 0121-3814, ISSN web: 2323-0126

Memorias, Sexto Congreso Internacional sobre Formación de Profesores de Ciencias. 08 al 10 de octubre de 2014, Bogotá

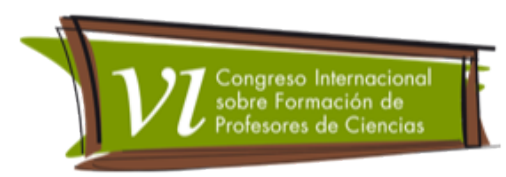

elementos básicos (actitudes, valores, creencias y formas de hacer las cosas propias de un contexto determinado), pautas de relación e interacción (entre los sujetos involucrados y también con el conocimiento) que son compartidos por los docentes que tienen que afrontar exigencias y limitaciones similares en el transcurso de muchos años (Hargreaves, 1996).

\section{Dos formas de asumir el conocimiento práctico del profesor: las propuestas de Clandinin y Schön.}

\section{Jean Clandinin.}

Según Clandinin (1986) el conocimiento práctico es un conocimiento experiencial, cargado de valor, propositivo y orientado a la práctica. Es, entonces, un conocimiento que se genera en la práctica de la enseñanza y que lo utiliza el profesor para planificar la acción y para desarrollarla abordando las dificultades que se generen en el proceso. Para este autor, el conocimiento práctico personal se forja y forma a partir de las situaciones experimentadas, es un conocimiento construido y reconstruido en la medida que el docente vive sus propias historias, las relata y las revive a través de procesos de reflexión (Clandinin, 1992). Y esto conduce a que el conocimiento práctico no sea objetivo ni independiente del docente; es más bien, la suma de todas sus experiencias; a su vez, es un conocimiento que no se puede separar del sujeto conocedor, depende de su historia y biografía.

El estudio de Clandinin y Connelly (1988) se centra en la idea de un conocimiento personal práctico que se activa con la forma de imágenes narrativas. Estas se ponen en juego en el proceso de enseñanza y están integradas por la historia personal, la actividad presente y las metas futuras del docente (Freeman, 2002). Concretamente ellos manifiestan que el conocimiento experiencial se organiza por medio de imágenes; y son estas imágenes personales las que le permite interactuar con el medio. Además, guardan un alto sentido afectivo, así como también moral y cognitivo.

En conclusión, Clandinin asume que el profesor es poseedor del conocimiento práctico que le pertenece, este es propio y se sustenta en la experiencia y la práctica personal. Lo anterior lleva a promover una investigación que mejore la práctica, ya que los docentes son auténticos protagonistas de su práctica. 
Revista Tecné, Episteme y Didaxis: TED. Año 2014, Número Extraordinario. ISSN Impreso: 0121-3814, ISSN web: 2323-0126

Memorias, Sexto Congreso Internacional sobre Formación de Profesores de Ciencias. 08 al 10 de octubre de 2014, Bogotá

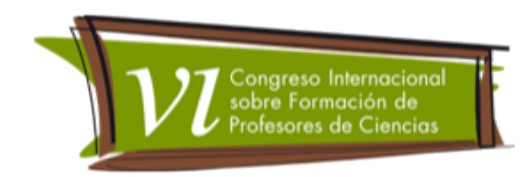

\section{Donald Schön.}

Schön (1987), citado por Jiménez, Cerrón y Bautista (1990) asume que el conocimiento práctico de un profesor se refleja en la habilidad para manejar la complejidad y singularidad del aula y resolver los problemas que se le presenten. Schön apunta que este conocimiento se genera por un proceso de reflexión durante la acción y después de ella.

El trabajo de Schön (1992) busca comprender como es la práctica del profesional, hay un interés por aquel conocimiento profesional que está ligado a la acción. Schön se resiste a considerar esta práctica como una aplicación instrumental de técnicas informada por un conocimiento formal. Se opone a la mirada positivista, en donde la aplicación de reglas, modelos, estándares provenientes del mundo teórico, riguroso, informan el accionar profesional.

Para Schön la práctica es singular, incierta, multidimensional, dinámica, ambigua conflictiva y compleja, exige un accionar que vaya más allá de la racionalidad y de la técnica. Es por ello que propone una "epistemología de la practica" (Schön, 1998) y se caracteriza por desarrollar la idea de un conocimiento que se construye desde la misma acción, y se sustenta en una racionalidad reflexiva (Montero, 2001).

\section{A modo de conclusión.}

Como lo afirma Valbuena (2009) en la producción de conocimiento pedagógico y didáctico se presenta un distanciamiento entre la comunidad académica que lo gesta y los profesores que a diario ejercen su profesión en las instituciones educativas. Se busca que los hallazgos de la investigación en ciencias, trasciendan la producción de conocimiento teórico, contribuyendo a la formación del profesorado de Ciencias, particularmente en procesos de formación inicial. Se hace imperativo que la profesión de los maestros se convierta en una actividad dinámica e integradora. Tal y como lo propone Porlan (2003), se debe identificar al profesor como un profesional que integra la construcción de un conocimiento particular, un conocimiento práctico fundamentado, así como la autonomía y las responsabilidades profesionales en relación con la disciplina y con la sociedad.

Así mismo, a partir de la reflexión teórica presentada, se espera encontrar claves acerca de la naturaleza teórica del conocimiento práctico y de las orientaciones 
Revista Tecné, Episteme y Didaxis: TED. Año 2014, Número Extraordinario. ISSN Impreso: 0121-3814, ISSN web: 2323-0126

Memorias, Sexto Congreso Internacional sobre Formación de Profesores de Ciencias. 08 al 10 de octubre de 2014, Bogotá

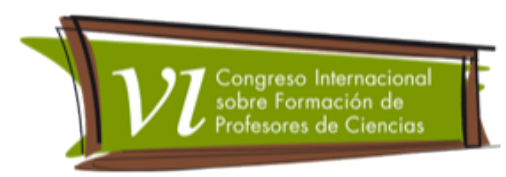

didácticas que favorezcan el aprendizaje significativo y relevante del conocimiento práctico.

\section{Referencias bibliográficas}

Alliaud, A. (1988). El maestro que aprende. Ensayos y Experiencias, 4 (23), 1-16.

Benejam, P. (1993). Los contenidos de la Didáctica de las Ciencias Sociales en la formación del profesorado. En Montero, L. y Vez, J.M. (Eds.). Las Didácticas específicas en la formación del profesorado (págs. 341-347). Santiago de Compostela: Tórculo.

Clandinin, J. (1986). Classroom Practice. Teachers imagines in action. London: The palmer press.

Clandinin, J. (1992). Narrative and story in teacher education. En Russell, T. y Munby, H. (Eds.). Teachers and teaching: from classroom to reflection (pp. 124-137). London: Falmer Press.

Clandinin, J. \& Connelly, M. (1988). Conocimiento práctico personal del los profesores: imagen y unidad narrativa. En Villar Angulo, L (Ed.). Conocimiento, creencias y teorías de los profesores: implicaciones para el curriculum y la formación del profesorado (pp. 39-61). Alcoy: Marfil.

Feldman, D. (1999). Ayudar a enseñar. Buenos Aires: Aiqué. Citado por Viscaíno, A (2008). El conocimiento práctico en la formación docente: una construcción histórica entre actores e instituciones. Revista Iberoamericana de Educación, (46), 1-11.

Freeman, D. (2002). The hidden side of the work: teacher knowledge and learning to teach. A perspective from North American educational Research on Teacher education in English language teaching. Lenguaje teaching, 35(1), $1-13$.

Gimeno-Sacristán, J. (1997a). El currículo institucional debe ser la sensatez colectivamente organizada. Novedades educativas, 9 (79), 12-13.

Gimeno-Sacristán, J. (1997b). Docencia y cultura escolar. Reformas y modelo educativo. Buenos Aires: Ideas. 
Revista Tecné, Episteme y Didaxis: TED. Año 2014, Número Extraordinario. ISSN Impreso: 0121-3814, ISSN web: 2323-0126

Memorias, Sexto Congreso Internacional sobre Formación de Profesores de Ciencias. 08 al 10 de octubre de 2014, Bogotá

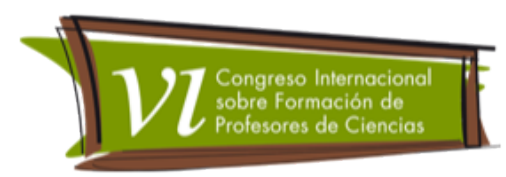

Hargreaves, A. (1996). Profesorado, cultura y posmodernidad. Madrid: Morata.

Jimenez, S.; Cerrón, C. y Bautista, A. (1990). El desarrollo del conocimiento práctico mediante procesos de investigación - acción. Revista Interuniversitaria de Formación de profesores, (9), 43-50.

Montero, L. (2001). La construcción del conocimiento en la enseñanza. En Marcelo, C. (Ed.). La función docente (págs. 47-83). Madrid: Síntesis.

Mosquera, C.J. y Furio-Mas, C. (2008). El cambio didáctico en profesores universitarios de química a través de un programa de actividades basado en la enseñanza por investigación orientada. Revista Didáctica de las Ciencias Experimentales y Sociales, 22; 115-154.

Pérez Gómez, A. (1988). Análisis didáctico de las Teorías del Aprendizaje. Málaga: Universidad de Málaga. Citado en Rodríguez Marcos, A. (1995) Un enfoque interdisciplinar en la formación de los maestros. Madrid : Narcea.

Perrenoud. P. (1995). Le travail sur l'habilus dans la formation des enseignants. Analyse des practiques et prise de conscience. Faculté de psychologie et de sciences de l'education, Génova (mimeo). Citado por Alliaud, A. (1998). El maestro que aprende. Ensayos y Experiencias, 4(23), 1-16.

Porlán, R. (1995). Constructivismo y escuela. Hacia un modelo de enseñanzaaprendizaje basado en la investigación. Díada, Sevilla

Porlán, R. (2003). Principios para la formación del profesorado de secundaria. Revista interuniversitaria de formación de profesorado, 17(001), 23-35.

Schön, D. (1983). The reflective practitioner. How professionals think in action. New York: Harper Colophon.

Schön, D. (1987): Educating the Reflective Practitioner. San Francisco: Jossey Bass. Citado en Jimenez, S.; Cerrón, C. y Bautista, A. (1990). El desarrollo del conocimiento práctico mediante procesos de investigación - acción. Revista Interuniversitaria de Formación de profesores, (9), 43-50.

Schön, D. (1992). La formación de profesionales reflexivos. Hacia un nuevo diseño de la enseñanza y el aprendizaje en las profesiones. Barcelona: Paidós. 
Revista Tecné, Episteme y Didaxis: TED. Año 2014, Número

Extraordinario. ISSN Impreso: 0121-3814, ISSN web: 2323-0126

Memorias, Sexto Congreso Internacional sobre Formación de Profesores de Ciencias. 08 al 10 de octubre de 2014, Bogotá

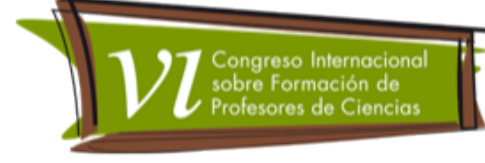

Schön. D. (1998). El profesional reflexivo. Como piensan los profesionales cuando actúan. Barcelona: Paidós.

Terhart. E. (1987). Formas de saber pedagógico y acción educativa o íqué es lo que se forma en la formación del profesorado. Revista de Educación. (284). 133-158.

Valbuena, E. (2009). Línea de investigación Conocimiento Profesional del Profesor de Ciencias. Revista Bio-grafia, 2 (2), 55-78

Viscaíno, A. (2008.) El conocimiento práctico en la formación docente: una construcción histórica entre actores e instituciones. Revista Iberoamericana de Educación, 46, 1-11. 